\title{
Aportes Bakhtinianos para escrita de si como estratégias de aproximação do aluno ao texto literário
}

Bakhtinian supports for self-writing as strategies to bring the student closer to the

literary text

Edjane Alves de OLIVEIRA*

Universidade Federal do Rio de Janeiro (UFRJ)

Maria de Fatima S. O. BARBOSA**

Universidade Federal do Rio de Janeiro (UFRJ)

\begin{abstract}
RESUMO: Este artigo apresenta reflexões e sugestões no âmbito das metodologias de ensinoaprendizagem, notadamente nas práticas de leitura e de escrita literárias. O objetivo é apresentar a escrita de si como instrumento para desenvolver o aprendizado dos conteúdos da literatura, conectado à realidade e à subjetividade dos alunos de uma escola do município do Rio de Janeiro. Para isso foi necessário um planejamento prévio de ações e de técnicas para subsidiar e motivar os alunos para a tarefa de escrever impressões de mundo, visando construir um arcabouço para incentivá-los a produzir escritos como transbordamento do eu, a partir da escrita de si. Os artefatos produzidos e analisados durante a pesquisa mostram previamente que ao verbalizar emoções e vivências na escrita autoral, o aluno assume perfil mais autônomo sobre sua aprendizagem, o que pode motivá-lo a melhorar seu rendimento escolar.
\end{abstract}

PALAVRAS-CHAVE: Leitor infanto-juvenil. Ensino de literatura. Escrita de si.

ABSTRACT: This article presents reflections and suggestions within the teaching-learning methodologies, notably in literary reading and writing practices. The objective is to present the writing of self as an instrument to develop the learning of the contents of the literature, connected to the reality and subjectivity of the students of a school in the city of Rio de Janeiro. For this, it was necessary to plan actions and techniques in advance to subsidize and motivate students for the task of writing impressions of the world, aiming to build a framework to encourage them to produce writings as an overflow of the self, from the writing of themselves. The artifacts produced and analyzed during the research show previously that when verbalizing emotions and experiences in authorial writing, the student assumes a more autonomous profile about his learning, which can motivate him to better school performance.

KEYWORDS: Infant-juvenile reader. Literature teaching. Self-writting.

\footnotetext{
${ }^{*}$ Mestre em Letras pelo Mestrado Profissional PROFLETRAS/UFRJ. Atualmente é professora da Secretaria Municipal do Rio de Janeiro (SME). E-mail: edjaneao@gmail.com

${ }^{* *}$ Doutora em Linguística pela Universidade Federal do Rio de Janeiro (UFRJ). Atualmente é professora no Departamento de Biblioteconomia da UFRJ. E-mail fatima.barbosa@facc.ufrj.br
} 


\section{Introdução}

Estudos sobre linguagem e construção de sentido, a partir de aspectos cognitivos e afetivos, consideram que a palavra ganha sentido dependendo do contexto de uso e das vivências afetivas de cada pessoa (VYGOTSKY, 1991). Sob a perspectiva dialógica da linguagem, Larossa (1994) entende que para exteriorizar a subjetividade, o sujeito faz a experiência de si mesmo em um jogo de verdade. Isso implicar dizer que ao planejar e elaborar estratégias de leitura e de escrita literárias, além de dar ênfase ao estudo de gênero e de estilo, deve-se prevalecer a preservação da força palavra, em sua essência.

Marcuschi (2008) acredita que, ao ler um livro, o leitor não só enxerga critérios gerais da textualidade como autor, texto, leitor, configuração linguística e situação comunicativa, mas também elementos linguísticos associados aos aspectos da realidade. Dessa forma, os modelos de ação comunicativa devem permitir que se opere em domínios discursivos, a partir de contextos reais da vida cotidiana. As emoções que o texto suscita, ao estabelecer a sensação de afinidade com a obra lida e o esforço em abstrair e se envolver com ela, de certo modo, possibilita que o sujeito se integre ao objeto de seu discurso e ao sistema da língua e se perceba sujeito esteticamente ativo, capaz de se apropriar de seu estilo e de sua composição, num processo de construção de sentido.

Bakhtin (2003, p. 309) considera que "cada texto é individual, único e singular" e sua essência estará "na fronteira de duas consciências, de dois sujeitos". Transpondo essa teoria para a práxis dos intramuros escolares, há que se perceber nas narrativas que os alunos apresentam em sala de aula um exercício de elaboração de ideias, de seleção de palavras e de organização da estrutura do texto como um exercício pessoal na busca pela construção de sentido. Espera-se, portanto, que a expressividade e a visão de mundo que se estabelecem nas narrativas escolares representem um verdadeiro diálogo do aluno consigo mesmo mediado por seu entorno.

Em se tratando do ensino de literatura, as escolas públicas no município do Rio de Janeiro tendem a priorizar o domínio do código escrito e a depreensão do significado, ao invés de priorizar a realização de leituras e de escritas esteticamente criativas, como parte de um complexo e criativo jogo de ideias e de emoções. Em sua prática, a escola oferece, como parte da metodologia empregada, uma diversidade de gêneros textuais, dentre eles, os textos literários, como artefatos para: ativar determinados conhecimentos prévios; 
identificar contextos, valores e pontos de vista do autor; decodificar e elaborar antecipações com o intuito de levar o aluno a apreender mecanismos linguísticos e discursivos. $\mathrm{Na}$ maioria das vezes, a literatura apresenta-se, nessa dinâmica, como pretexto para a descrição da forma e do funcionamento da língua.

O desafio de quem trabalha com o ensino de texto literário é perceber que o processo que o aluno percorre ao ler e criar seu texto é pessoal. A partir da boa leitura e da escrita de textos literários, através de uma dinâmica interior e criação de enunciados, ele pode, segundo Faraco (2009), fazer emergir uma multidão de vozes interiorizadas.

Ao repensar estratégias que possam colaborar com o ensino da literatura nas escolas públicas, deve-se ter em mente que o homem é e sempre será "uma equação do eu e do outro" (BAKHTIN, 2003, p. 99). Dessa forma, entende-se que o ato de criar, a partir de leituras feitas em sala de aula, possa servir como estímulo para a leitura e a produção escrita, desde que o aluno perceba o texto como uma possibilidade de múltiplas interpretações e sensações.

Nessa perspectiva, esse trabalho apresenta uma proposta metodológica para trabalhar a escrita de si em sala de aula a partir dos gêneros que transitam pelo espaço autobiográfico. Foi dada atenção à questão da afetividade na leitura e na produção de texto. A metodologia visa a possibilitar o encontro do sujeito leitor com o seu discurso como sujeito esteticamente ativo.

O capítulo a seguir traz reflexões sobre aspectos relevantes à vida escolar de um leitor em formação, pois precisamos enxergar um pouco da realidade social do leitor brasileiro e o reflexo do ensino de literatura no país.

\section{Reflexões sobre a formação do leitor-aluno}

Para entendermos um pouco a realidade social do leitor-aluno de uma escola do município do Rio de Janeiro em nível micro e o reflexo disso para o ensino de literatura no país, em nível macro, tomemos como base a $4^{\mathrm{a}}$ edição da pesquisa Retratos da Leitura no

Revista Moara, n. 56, vol. 2, jan-jul 2021 ISSN: 0104-0944 
Brasil, realizada em 2016. Essa pesquisa segue os parâmetros do Centro Regional para el Fomento del Libro en América Latina y el Caribe (CERLALC), que permite a comparação de dados entre os países da região. A Fundação Pró-Livro, realizadora da pesquisa, e o Instituto Ibope Inteligência, que a executa, em consonância com o CERLALC, aprimoraram a pesquisa e trouxeram algumas novidades em relação a 2011. De acordo com os dados coletados, 104,7 milhões de brasileiros se declararam leitores, havendo um aumento considerável nos índices de leitura per capita de 2011 para cá.

Nos resultados da pesquisa citada acima, observam-se alguns dados relevantes sobre o perfil do leitor brasileiro, que está relacionado com seu perfil de leitor literário. Através da coleta de dados, em nível nacional, de 5.012 entrevistados, a amostra revela que quanto maior a escolaridade e a classe social maior a proporção de compradores de livros.

Chama-nos a atenção a faixa etária que mais interessa a esse estudo, ou seja, alunos do ensino básico. A pesquisa revela que, atualmente, a faixa etária dos entrevistados que mais acessa a internet para leitura de livros é a de 18 a 24 anos. Mas, mesmo tendo subido de 81 milhões de brasileiros com acesso à internet, em 2011, para 127 milhões, em 2015, cerca de 50\% dos leitores indicaram como meio de acesso ao livro, empréstimos com parentes ou em bibliotecas. Outros $23 \%$ só leem livros quando são presenteados, ou seja, os espaços de leitura e a influência familiar têm sua importância na formação do leitor.

Em relação às atividades relacionadas à leitura que realizam na internet, os itens mais indicados são:

leitura de notícias e informações em geral (52\%); estudo e pesquisas para a realização de trabalhos escolares (35\%) e aprofundamento no conhecimento a respeito de temas de interesse pessoal (32\%). A leitura de livros fica em sexto lugar, com 15\%. (FUNDAÇÃO PRÓ-LIVRO, 2016)

Na pesquisa, 33\% dos respondentes declararam que tiveram influência de alguém para começar a ler. A figura materna - mãe ou responsável do gênero feminino - aparece como a maior influenciadora nesse quesito; os professores e as professoras representam apenas $7 \%$ e a figura paterna, $4 \%$. A influência dos professores e professoras de apenas $7 \%$ no processo de aquisição de leitura deveria ser um alerta para os pesquisadores e profissionais da educação, se entendermos que a escola não está atuando, como se esperaria, no processo de formação do leitor literário.

De modo geral, o ensino da literatura talvez esteja refletindo uma prática que, ao invés de aproximar obra e leitor, esteja no caminho inverso. Lajolo (1994) afirma que há 
um desencontro entre literatura e jovens e, para a escola, parece um desencontro maior, pois há muitos alunos que não leem, escrevem mal e professores também. Além dos fatores apontados na pesquisa anterior, outros também podem ter colaborado para o possível distanciamento do aluno ao texto literário. Sob o ponto de vista de Scheffer (2019), o que acontece na prática escolar é uma transferência do texto literário de seu suporte físico para as páginas do livro didático, outro tipo de gênero. Há ainda pouca oferta de literatura voltada para o universo infanto-juvenil como: diário, teatro, memórias e cartas que permeiem a fronteira entre a ficção e a não-ficção.

Nesse sentido, entende-se que o aluno do segundo segmento do ensino fundamental transita naturalmente na fronteira entre a não-ficção e a ficção e os gêneros com características autobiográficas podem ser um caminho que o conduza a se aproximar gradativamente da literatura. Se considerarmos a escola como um laboratório e cada escrita do aluno uma amostra, todo diagnóstico, a partir da escrita do aluno, forneceria pistas para o direcionamento da ação pedagógica que, com o auxílio de estratégias diversas, remeteria à maior eficácia no aprimoramento do processo de formação do leitor. As competências e as habilidades que instrumentalizam e dão norte ao professor, ao se basearem na observação dessas amostras, poderiam aumentar as probabilidades de êxito no processo de formação desse leitor em potencial.

Assim, entendemos que, tratando-se de um espaço carregado de subjetividades, a sala de aula necessita de metodologias que privilegiem a escrita de si, através de gêneros que transitem no espaço autobiográfico, como estratégia para dar voz aos alunos, principalmente, a voz que vem do fundo da sala de aula, voz abafada que tanto tem a dizer.

\subsection{O aluno-leitor real}

O papel da escola atualmente pressupõe formar cidadãos globais, que saibam lidar com diferenças interculturais, através das habilidades próprias do século XXI. Dudeney (2016), em seus estudos sobre letramento digital, afirma que a sociedade caminha no sentido de desenvolver competências que promovam a interação com um mundo digitalmente interconectado. Há, portanto, a necessidade de investir em habilidades como: criatividade, inovação, senso crítico, capacidade de resolução de problemas, trabalho em equipe, autonomia e flexibilidade, num processo de aprendizagem permanente. Dessa 
forma, qual perfil de leitor em que queremos investir, em se tratando de ensino da literatura nas escolas?

Há muitos aspectos importantes que interferem na vida de um leitor em formação. Se partirmos do panorama geral do perfil do leitor brasileiro à realidade plural de uma sala de aula, na qual circulam narrativas no dia a dia da escola, perceberemos que o ensino da literatura, nos anos finais do ensino fundamental, pode investir mais no encontro e na interação entre os diferentes leitores e diferentes obras, de modo que os alunos se sintam instigados a passar por experiências de leitura, reconhecendo suas próprias interpretações como possíveis e percebendo a leitura do texto literário como uma prática social e afetiva.

O leitor autônomo real é aquele que aprimora sua percepção estética e ideológica e trabalha o implícito no texto. Como o sujeito-leitor contemporâneo ele é capaz de produzir uma escrita própria e espontânea. Atualmente, a escola tende a formar leitores padrões e se esquece dos leitores reais, plurais e empíricos. Ao criar estratégias que contribuam para uma prática de leitura que estimule a autonomia dos leitores literários infanto-juvenis, no espaço intersubjetivo da sala de aula, devemos ter em mente também o que propõe Dalvi (2013), que se faça da leitura literária uma sedução, um desafio, um prazer, uma conquista; não só uma prática, mas um hábito incorporado ao cotidiano escolar. Quanto mais flexível e ativo for o ensino da literatura nas escolas, mais os alunos poderão se aproximar da leitura literária de forma autônoma e prazerosa. O caminho literário que o leitor percorre é pessoal e, em termos de leitura das obras que permeiam o universo dos jovens leitores e seus conflitos psicológicos, percebe-se uma inclinação que transita pela tênue fronteira entre ficção e não ficção.

Segundo Santaella (2019) há quatro tipos de leitores de livro do século XX: o leitor contemplativo, do texto impresso, que demonstra uma intimidade entre ele e o livro, a partir da leitura silenciosa, individual e solitária; o leitor movente, que lê imagens na foto, na publicidade e no cinema; o leitor imersivo que, com o surgimento da internet, interage nas infovias dos ambientes da web, e o leitor ubíquo que tem acesso à informação em qualquer lugar onde possa estar. Santaella (2019) propõe que se mantenha, nos ambientes educacionais, habilidades cognitivas próprias do leitor contemplativo, pois este desempenha a função reflexiva que só a leitura do livro pode nos trazer. Para a autora, não importa o dispositivo digital porque é o silêncio da leitura contemplativa que pode "acionar a mente para a incorporação e memorização de um conteúdo que vai se construindo passo a 
passo, em teias de sentidos que crescem na sequência da entrega do leitor ao texto" (SANTAELLA, 2019, p. 26).

Formar leitores autônomos reais, no exercício de linguagem e na relação entre a obra e o leitor, de acordo com as experiências de leitura e de mundo do aluno, seria levá-lo a percorrer o fluxo interpretativo da consciência e a interagir com o inconsciente, corroborando com Petit (2008, p. 38) quando ela afirma que o nosso pensamento se dá a partir do que nos é lançado por outros.

A relevância do ensino da literatura presente no constructo teórico dessa pesquisa, em confluência com a voz do aluno, presente em suas produções orais e escritas, desenha um caminho a ser percorrido no processo de leitura e escrita literárias como possibilidade de verbalizar emoções e vivências.

\subsection{O aluno e a escrita motivada por uma intenção artística}

Bakhtin (2003) apresenta um sujeito esteticamente ativo e situado fora dele, como produto de um ponto de vista estético, criador e ético. A realização da criação verbal em seu valor estético, segundo Bakhtin (2003), pode ser comparada com a ação de um esportista que precisa se concentrar dentro de si e de dentro de si mesmo calcular os seus movimentos, contrair-se à pura unidade interna, deixar de ver e ouvir o que quer que venha de fora, reduzir a si mesmo por inteiro e ao mundo à pura sensação, "deixando que o visível apenas complete o vivenciável de dentro" (BAKHTIN, 2003, p. 45).

Em relação à construção do eu e à escrita, Wallon (1975 apud La Taille, 2016, p. 95) afirma que se trata de um processo condenado ao inacabamento, pois persistirá sempre, dentro de cada um, como um "fantasma do outro", de sub-eu (sous-moi). Os estados passionais momentâneos podem interferir nas fronteiras que separam o mundo interno do mundo externo. Nesse drama, o eu frágil precisa da admiração do outro para completar a sua construção.

Ao construir sua narrativa, há um distanciamento necessário e consciente do autor, que se dá de forma criativa e estética, no exercício de percepção de vozes da personagem. Isso se dá "em cada traço, cada acontecimento, cada ato, cada pensamento e sentimento, como acontece na própria vida" (BAKHTIN, 2003, p. 3). Para o autor, a estrutura interna da narrativa estabelece um elo entre a consciência do autor e a consciência da consciência,

Revista Moara, n. 56, vol. 2, jan-jul 2021 ISSN: 0104-0944 
ou seja, ele enxerga e conhece tudo da personagem, que é inatingível ao próprio personagem. Bakhtin considera que a fórmula basilar esteticamente produtiva se constitui por uma:

\begin{abstract}
relação de tensa distância no espaço, no tempo, nos valores e nos sentidos que permite abarcar integralmente personagem, difusa de dentro de si mesma e dispersa no mundo preestabelecido do conhecimento e no acontecimento aberto ao ético, abarcar a ela e sua vida e completá-la até fazer dela um todo com os mesmos elementos que de certo modo são inacessíveis a ela mesma e nela mesma: com a plenitude da imagem externa, o fundo que está por trás dela, a sua relação com o acontecimento da morte e do futuro absoluto, etc., justificá-la e acabá-la, desconsiderando o sentido, as conquistas, o resultado e o êxito de sua própria vida orientada para o futuro (BAKHTIN, 2003, p. 25).
\end{abstract}

O autor quando cria seu texto assume pretensões ético-cognitivas que, segundo Bakhtin (2003, p.42), é um fundo esteticamente utilizado que se transforma em momento de desmascaramento. Há a transgrediência axiológica dos elementos que asseguram à personagem o acabamento estético como aspecto inorgânico da autoconsciência.

Nossa tarefa imediata é examinar aqueles valores plásticos-picturais e espaciais que são transgredientes à consciência e ao mundo da personagem, à sua diretriz ética-cognitiva do mundo, e o concluem de fora, a partir da consciência do outro sobre ele, da consciência do autor-contemplador (BAKHTIN, 2003, p. 42).

Trabalhar o texto literário em sala de aula contribui para dar voz e visibilidade ao aluno em seus juízos de valor e em suas emoções, situando-o em si e fora de si. Possibilita também que ele se integre com o objeto de seu discurso e com o sistema da língua, constituindo-se como sujeito esteticamente ativo e capaz de determinar o enunciado ao se apropriar do seu estilo e de sua composição.

Nesse contexto, a escrita com características autobiográficas retrata a noção de verdade associando-se a um estrato profundo, inconsciente e inatingível, que só acontece pela mediação do ficcional. Segundo Klinger (2012), um texto literário sempre privilegia a função artística sobre a referencial e, no "espaço autobiográfico", o leitor poderá jogar com equívocos, armadilhas, máscaras, desdobramentos e perturbações de identidade que constituem diversas focalizações entre o ficcional e o referencial, de acordo com suas crenças" (ARFUCH, 2005 apud KLINGER, 2012, p. 39).

Rago (2013), em seu livro A aventura de contar-se: feminismos, escrita de si e invenções de subjetividade apresenta a 'escuta' como um movimento que visa a mudar o 
modo de cada um se relacionar consigo mesmo e com o meio social. Ao discorrer sobre técnicas de si, Rago (2013) ressalta que as memórias, ao longo do tempo, ficaram restritas a espaços fechados, compartilhadas apenas entre amigos e familiares, na esfera da intimidade. Entretanto, ao se tornarem visíveis, as memórias tornam-se emblemáticas, pois passam a exercitar a articulação entre o subjetivo e o coletivo, na busca pela transformação de si e da sociedade como um todo (RAGO, 2013, p. 59).

As importantes contribuições do aporte teórico aqui apresentadas, dentre inúmeras outras que, de certa forma, estão interiorizadas, nos impulsionam a um fazer pedagógico, dentro de uma concepção dialógica, que invista em múltiplos olhares, perspectivas e possibilidades para o ensino da literatura, nos anos finais do segundo segmento do ensino fundamental. Para tanto, a proposta metodológica desse estudo visa oferecer ao aluno, através da literatura, a possibilidade de discutir verdades e abordar de conflitos sociais e existenciais, no sentido de motivá-los a ampliar sua visão de mundo e de si mesmo, através da escrita de si.

Quando o aluno volta seu olhar de fora para dentro, descobrindo sua potencialidade para a escrita, e quando ele compartilha entre todos a sua produção, pode se sentir motivado a realizar leituras e escritas literárias no espaço da sala de aula, tornando-se, gradativamente, mais autônomo na prática da leitura e da escrita.

\section{Metodologia}

Conforme descreveremos a seguir, essa proposta apresenta sete estratégias pedagógicas (doravante, E1... E7), constituídas por atividades de leitura e/ou de produção textual com a perspectiva da escrita de si. Cada estratégia tem seus desdobramentos viabilizados por ações, sugestões e práticas, organizadas metodologicamente, a partir de atividades como: leituras de contos, crônicas, poemas, cartas pessoais, diários, memórias, enfim, gêneros que transitam pelo espaço autobiográfico como motivação para a leitura e a escrita.

A metodologia foi testada em alunos dos anos finais do segundo segmento do ensino fundamental em escola pública municipal localizada na zona oeste da cidade do Rio de Janeiro e 265 alunos participaram efetivamente da pesquisa.

Revista Moara, n. 56, vol. 2, jan-jul 2021 ISSN: 0104-0944 


\subsection{Desenvolvimento da Proposta Metodológica}

Inicialmente, foi aplicado um questionário com a participação de 104 alunos do sexto ao nono anos de escolaridade. Esse questionário teve como objetivo coletar dados que nos indicassem hábitos de leitura e de conhecimentos de literatura do aluno. As questões estavam relacionadas à leitura de texto literário, ao hábito de leitura, a sua autonomia para a escolha dos livros e o seu grau de proximidade com os livros de literatura.

As respostas a esse questionário foram separadas por ano de estudo e lidas uma a uma. Depois disso, foram agrupadas por semelhanças gerais. A análise dos dados mostrou que a motivação para a leitura era baixíssima, corroborando com os dados da pesquisa Retratos da leitura no Brasil (FUNDAÇÃO PRÓ-LIVRO, 2016).

Numa visão geral desse diagnóstico inicial, alunos do sexto ano demonstraram gostar de ler e ouvir narrativas e sentiam mais dificuldade em se concentrar na leitura de textos longos. O sétimo ano nos alertou para a necessidade de uma prática pedagógica mediada pela escola que oferecesse um trabalho mais dinâmico e de maior autonomia na escolha de textos literários, em diferentes suportes. O oitavo ano é o período mais crítico. As turmas desse período apresentaram mais desinteresse pela leitura. Afirmam que o problema está nas práticas de leitura que não atendem as suas expectativas em relação ao texto literário. Os alunos do nono ano ressaltaram a preferência por textos produzidos em mídias sociais e aplicativos como, por exemplo, Wattpad (aplicativo desenvolvido para produção de histórias). Para esses adolescentes, esse espaço proporciona maior autonomia, facilidade de acesso e possibilidade de narrar suas experiências de vida sem que suas identidades sejam reveladas sem o monitoramento da escola. Esses resultados nos motivaram a criar atividades que mobilizassem os alunos para a leitura e a escrita.

Depois da análise do questionário, foi realizado o planejamento das atividades, conforme descrito abaixo. As etapas foram avaliadas uma após outra, visando um retorno que nos indicasse se estava havendo perdas ou ganhos com as atividades. As avaliações de cada etapa foram realizadas por enquetes entre os alunos, por perguntas diretas em sala de aula e por observação presencial do próprio professor da turma. $\mathrm{O}$ retorno era dado pelas declarações orais e escritas que retratavam entusiasmo, surpresa e depoimentos captados pela percepção profissional do professor. Nessa etapa do trabalho, participaram das ações

Revista Moara, n. 56, vol. 2, jan-jul 2021 ISSN: 0104-0944 
interventivas 161 alunos do oitavo ano, por ser esse o ano que demonstrou maior desinteresse pela leitura e maior criticidade em relação ao ensino da literatura da escola.

A seguir, serão apresentadas as estratégias produzidas nessa pesquisa, E1 a E7, com respectivos exemplos produzidos pelos alunos. Constitui-se de ações pedagógicas de leitura e/ou produção textual, exercitando a multiplicidade de olhares, a partir da escrita de si.

Quadro 1 - Estratégia 1

Atividade - Escrita de parágrafo descritivo

Objetivo - Exercitar o distanciamento entre autor e obra como exercício do olhar para fora, uma das características dos gêneros confessionais.

Ação pedagógica - O aluno deverá escrever parágrafo descritivo que pode ser: de personagens conhecidos da literatura infanto-juvenil, de pessoas famosas, de alguém da escola, de espaços da escola ou de outros espaços conhecidos por todos; pode ser também de objetos com valor afetivo.

Sugestão de atividade - ler em voz a alta a descrição feita para que os colegas de turma tentem adivinhar do que ou de quem se trata.

Exemplo:

Sua estatura é baixa e seu corpo esbelto. Sua pele negra, seus cabelos são pretos e cacheados, sua cabeça tem um sinal branco, em suas mãos delicadas existem três anéis, suas unhas sempre pintadas com esmalte escuro, seu sorriso é lindo, contagiante e perfeito, usa mochila preta, seu tênis é branco. Ela é menina, tem olhos castanhos escuros, lábios morenos e sobrancelhas grossas. Você já sabe quem é?

Fonte: OLIVEIRA (p.65, 2018)

Quadro 2 - Estratégia 2

Atividade - Escrita do diário

Objetivo- Levar o aluno a olhar para suas memórias.

Ação pedagógica - O aluno deverá estabelecer um diálogo por escrito com um interlocutor, por meio do gênero diário, através de uma abordagem afetiva e simbólica, que remeta a suas expectativas e vivências.

Sugestão de atividade - o aluno deverá escrever uma página de diário, contando um momento vivido com uma pessoa especial de sua família ou um amigo real ou fictício.

Exemplo:

Querido diário,

Meus pais se separaram. Minha mãe foi embora de casa e levou quase tudo de dentro da casa, deixando meu pai sem nada. O motivo da separação deles dois foi a bebida, meu pai bebe muita cerveja, muita mesmo, e também só meu pai podia sair para beber e curtir com os amigos e ela não podia. Então, ela se

Revista Moara, n. 56, vol. 2, jan-jul 2021 ISSN: 0104-0944 
cansou, juntou as coisas e foi embora. Recado: eles voltaram em novembro e meu pai mudou o jeito de ser.

Fonte: OLIVEIRA (p. 66, 2018)

Quadro 3 - Estratégia 3

Atividade - Produção de autobiografia do leitor literário

Objetivo - Provocar no aluno o olhar de si enquanto leitor e a percepção e influência do discurso do outro sobre si mesmo.

Ação pedagógica - Escrever sobre sua experiência de leitura literária.

Sugestão de atividade - $\mathrm{O}$ aluno deverá escrever um texto contando a influência da literatura em sua vida, a partir de pessoas bem próximas que liam ou contavam histórias que estão vivas em sua memória.

Exemplo:

Meu caos e a literatura

Tudo se inicia na antiga locadora logo abaixo da minha casa, aos meus oito anos. Em cima da bancada, havia alguns gibis à venda por 2 reais. Márcia, a dona do tal lugar, sorria simpaticamente enquanto eu escolhia qual comprar. Mal sabia eu que dali em diante me viciaria em ler. Acima de mim, o caos começou. E eu inocente, só reparei quando subi. Meu pai, meu querido e calado pai, era viciado em bebida. Enquanto eu lia meus livros coloridos, fui reparando nas cinzas que minha casa estava se tornando. (...)

Fonte: OLIVEIRA (p. 67, 2018)

\section{Quadro 4 - Estratégia 4}

Atividade - Leitura de textos literários do acervo da sala de leitura da escola.

Objetivo - Lançar múltiplos olhares sobre um mesmo texto literário.

Ação pedagógica - Os alunos são convidados a escolher um dos livros do acervo da sala de leitura, em dupla ou trio. Um deve passar para o outro do mesmo grupo o mesmo livro, fazendo-o circular entre o grupo. Após a leitura, os alunos deverão discutir sobre as sensações despertadas pelo livro e comparar com a leitura do outro.

Sugestão de atividade - realizar individualmente uma ficha de leitura que conste nome do autor e do ilustrador, título do livro, pequeno resumo e comentário com indicação ou não do livro.

Exemplo - Título do livro: Ame o que é seu

Autor: Emily Giffin

Gênero textual: Conto

Resumos:

Leitor 1- Este livro conta a história de uma mulher que, após reencontrar com alguém do passado, começa a questionar tudo.

Leitor 2- O livro conta sobre o reencontro de Ellen com seu ex-namorado. Os sentimentos de Ellen parecem ser estranhos para alguém casada, que ama seu marido. Ellen não pode contar a ninguém, pois ela acha isso uma deslealdade com seu marido.

Leitor 3- Esse livro conta a história de uma mulher que, após encontrar uma pessoa do passado, começa a

Revista Moara, n. 56, vol. 2, jan-jul 2021 ISSN: 0104-0944 
questionar suas escolhas e seus valores.

Comentários:

Leitor 1- Este livro impactou muito. Tudo o que acontece com a protagonista Ellen, as atitudes que ela toma e o modo em que ela lida com a situação me fez pensar mais e priorizar coisas mais importantes em minha vida.

Leitor 2- Achei este livro ótimo. Eu realmente recomendo. Em algumas partes você se identifica com o que o livro fala.

Leitor 3- Esse livro é mega interessante, porque há tipo um flashback da personagem.

Fonte: OLIVEIRA (p. 69, 2018)

Quadro 5 - Estratégia 5

Atividade - Escrita de uma carta de cunho social e afetivo.

Objetivo - Levar o aluno à busca de si e do olhar perceptivo do outro.

Ação pedagógica - Escrever uma carta de cunho social e afetivo.

Sugestão de atividade - os alunos deverão escrever cartas e entregar pessoalmente a uma instituição. Pode ser: asilo, orfanato e/ou hospital. No caso dessa pesquisa, foi escolhido um asilo para idosas com deficiência visual. Ao entregar as cartas, os próprios alunos deverão lê-las em voz alta.

Exemplo:

Oi, vó, tudo bem?

Quanto tempo, né? Sinto muito sua falta, faz um bom tempo que eu não te vejo, que eu não sinto seu cheiro, que eu não como sua comida. A senhora sabe que eu não tenho muita criatividade, mas quando se trata de alguém que eu amo, eu tiro a criatividade de onde não tem. Queria te agradecer por fazer parte da minha vida e por ser tão legal e simpática comigo. A senhora é uma guerreira, sempre trabalhou muito pra criar seus filhos e pra fazer sua casinha. Vovó, te amo e estou com saudades.

Fonte: OLIVEIRA (p. 70, 2018)

\section{Quadro 6 - Estratégia 6}

Atividade - Escrever uma paródia, a partir de uma canção apresentada pelo professor.

Objetivo - Provocar o olhar de si.

Ação pedagógica - A partir de uma música, reescrever a letra com questões próprias de um adolescente, como exercício de autoimagem, ao suscitar questionamentos próprios de sua idade.

Sugestão de atividade - Para essa atividade, como sugestão, foi apresentada a música Oito anos, de Paula Toller.

Exemplo:

Meus 13 anos

Por que você tem acne

E eu não?

Por que você é alto e ele não?

Por que você produz testosterona e ela progesterona?

Essas mudanças ocorrem em que momento?

Revista Moara, n. 56, vol. 2, jan-jul 2021 ISSN: 0104-0944 
Por que sua voz começou a mudar?

Por que os ombros começam a se alargar?

Por que a cintura dela começou a afinar e suas coxas e quadris aumentar?

Por que você têm músculos maiores que os meus?

Por que ela começou a sangrar?

Por que agora ela tem que se cuidar?

Por que ela começou a fecundar?

Por que os hormônios mexem com a gente?

Por que eu e ela somos tão diferentes?

Os hormônios modificam a gente?

Por que nós crescemos?

Por que nós aprendemos?

Por que nosso corpo produz insulina e glucagon?

Os hormônios são responsáveis por causar doenças na gente.

Mas voltando a perguntar, em que fase da nossa vida ocorrem

essas mudanças e modificações no nosso corpo?

Ah, mas, é claro, só pode ser a puberdade!

$\mathrm{C}-8^{\circ}$ ano

Fonte: OLIVEIRA (p. 75, 2018)

Quadro 7 - Estratégia 7

Atividade - Leitura de um texto literário

Objetivos - O professor deverá apresentar uma narrativa envolvente, com marcas autobiográficas, de modo que esta estratégia seja o corolário das estratégias anteriores. O aluno deve agora chegar ao ponto de se aproximar de forma prazerosa e significativa da literatura.

Ação pedagógica - a partir da leitura de um o conto descritivo-afetivo, os alunos devem observar as características físicas e emocionais de alguém de sua relação afetiva.

Sugestão de atividade - Nessa pesquisa, foi utilizado o conto Olhos D'Água, de Conceição Evaristo. A partir desse conto, os alunos puderam observar a cor dos olhos de alguém de seu convívio familiar e produzir um texto descrevendo esse olhar.

Exemplo:

A cor dos olhos de minha mãe

Os olhos da minha mãe... Nunca tinha reparado nos olhos de minha mãe... Eu sempre fico na janela reparando meus olhos, porque sempre quis que eles fossem claros, e meu olho ficou claro! E daí, um dia aconteceu uma coisa comigo, muito legal e de propósito, sentei naquela janela que batia o sol e conversei com ela... e vi o olhar sincero dela sorrindo... e aí fiquei muito feliz...E até hoje me pergunto qual a cor dos olhos de minha mãe, porque, naquele momento, esqueci os olhos e foquei na felicidade!

Fonte: OLIVEIRA (p. 80, 2018)

As sete estratégias apresentadas fazem parte de um encadeamento progressivo para provocar no aluno um interesse gradativo, prazeroso e lúdico, característico da formação do leitor-literário.

\subsection{A análise de dados da proposta metodológica}

Revista Moara, n. 56, vol. 2, jan-jul 2021 ISSN: 0104-0944 
Em linhas gerais, a média de realização das tarefas atingiu cerca de $70 \%$ dos alunos do segundo segmento do ensino fundamental. A variação para mais e para menos revelou que, para atingir o objetivo dessa proposta, foi essencial a busca por gêneros textuais e estratégias pedagógicas que aproximassem o leitor ao texto literário.

Ao observarmos o resultado da E1 à luz do arcabouço teórico de Bakhtin (2003) podemos considerar que houve atribuição de significado linguístico associado a uma realidade concreta, dando expressão ao que foi escrito. $\mathrm{O}$ aluno ao descrever uma colega atribui juízo de valor, afetividade e emoção sob o ponto de vista de seu olhar para o outro.

O diário é um gênero que aproxima o aluno da escrita mais autoral e afetiva, como podemos ver no trecho da E2. O tema da separação de pais, o vício, a morte de uma pessoa próxima, aniversários, passeios, presentes, surpresas, acidentes, tudo que envolve o dia a dia de todos nós, está guardado na memória. Nesse sentido, o aluno, ao reconhecer a si mesmo em seus registros, evidencia o que Foucault defende como constituição do sujeito que, como objeto de si mesmo, passa a "analisar-se, decifrar-se, reconhecer-se como um domínio do saber possível” (FOUCAULT, 1984 apud LAROSSA, 1994, p. 118)

Ao considerar características de uma obra de auto-informe-confissão, Bakhtin (2003, p.128) leva-nos a perceber que a confissão se revela como forma bruta para uma elaboração estética e em que personagem e autor são um só. No trecho da E3 há indícios de um leitor-autor autobiográfico. O texto foi produzido por uma aluna do nono ano, em sala de aula e, ao entregá-lo como tarefa, disse que se tratava de um pouco de sua história de vida relacionada à sua intimidade com a literatura.

Em E4, a estratégia de leitura em grupo de um mesmo livro possibilita trabalhar a estrutura narrativa dos gêneros em relação aos aspectos sociais e interacionais do discurso. Nesse sentido, ao atentar para os estudos de Rouxel (2013), podemos inferir que a leitura sensível da literatura enquanto arte poderá favorecer a crescente percepção de si e do outro em seu convívio social.

Foucault (1992) ressalta as implicações positivas que podem advir da escrita autoral como matéria-prima. Nas cartas, um gênero de cunho autoral, há muitos sentimentos envolvidos que podem constituir uma maneira de se preparar para eventos de sua própria vida. Em E5, percebe-se que o aluno escreve a carta com palavras cheias de afeto como se fosse realmente para sua avó.

Revista Moara, n. 56, vol. 2, jan-jul 2021 ISSN: 0104-0944 
A partir do gênero canção, em E6, o aluno cria uma paródia como estratégia de escrita de si, representando uma outra voz, que aciona suas vivências ao produzir o texto. Além da sonoridade, ritmo e versos, o aluno faz emergir inquietações resultantes de um exercício de olhar para dentro de si ao estabelecer um diálogo social de uma voz interiorizada (FARACO, 2009).

Em E7, após a leitura do texto literário, o aluno descreve os olhos da mãe, empregando estratégias de escrita literária ao buscar na memória o que viu e sentiu no olhar de sua mãe. Esse exercício de olhar, presente em todas as atividades dessa proposta metodológica, conduz à experimentação e à identificação do aluno com o tex to literário.

As estratégias apresentadas aqui buscam aproximar o aluno, gradativamente, ao texto literário e à construção de sentido.

\section{Considerações finais}

Para empreender essa pesquisa, encontramos algumas variáveis próprias do contexto escolar como: aceitação e interesse pelas atividades por parte dos alunos; abordagem por parte do professor; receptividade por parte da turma e de cada aluno; expectativa criada a cada proposta do próprio pesquisador; dificuldade para manter a constância nas atividades de leitura e de escrita; grau de autonomia exigido para o aluno em cada ação proposta; capacidade de expressar afetividade por parte do aluno e/ou professor, item fundamental para a realização das tarefas; comprometimento pela busca da construção de sentido, dentre outras. Esses fatores, se não forem trabalhados pacientemente pelos envolvidos no processo, podem não trazer o êxito esperado. Donde se conclui que o envolvimento dos sujeitos em sala de aula (professor-alunos, alunos-alunos) deve ser condição sine qua non para a eficácia da proposta. Sabemos que esse espaço reflete um extrato da realidade social, através das vozes plurais dos alunos, em suas colocações, seus questionamentos e em sua capacidade de transformação, desde que estimulados a isso, porém, muitas vezes, são vozes silenciadas. Nessa complexa dinâmica de sala de aula estão o mundo, o desejo, o tédio, a solidão, a violência, os limites, o sonho, dentre outras questões imprescindíveis no dia a dia de todo ser humano. Nesse cenário, a literatura oferece algumas chaves para acessar nossos labirintos interiores, tornando-nos mais sujeitos de nós mesmos na construção de nossa história de vida.

Revista Moara, n. 56, vol. 2, jan-jul 2021 ISSN: 0104-0944 
Ao propor uma metodologia para o ensino de literatura no segundo segmento da educação básica, sob a ótica Bakhtiniana, assumimos que a criação verbal, em muitos aspectos, é inconsciente e polissêmica e que o sujeito-leitor encontra na obra literária a possibilidade de acessar diferentes visões de mundo. Com isso, propomos que a escola construa uma relação sólida e solidária com obra, autor, leitor e vida, ao entendermos que, através do ensino da literatura, podemos exercitar no aluno a leitura contemplativa de um mundo globalizado. Ao estabelecer um diálogo constante entre sua voz interior e as vozes multifacetadas desse mundo, estaremos ajudando a formar cidadãos globais.

Finalizando, essa proposta atende ao objetivo desse estudo que, em linhas gerais, é levar o aluno a desenvolver uma escrita mais autoral, afetiva e criativa, e exercitar a leitura contemplativa e autônoma dos textos literários, oferecidos em escolas de segundo do ensino fundamental, dentre outros espaços de leitura.

\section{REFERÊNCIAS}

BAKHTIN, M. Estética da criação verbal. Tradução de Paulo Bezerra. $4^{\mathrm{a}}$ ed. São Paulo: Martins Fontes, 2003. - (Coleção Biblioteca Universal)

DALVI, M. A. Literatura na escola: propostas didático-metodológicas. In: DALVI, M. A.; REZENDE, N. L.; JOVER-FALEIROS, R. (Org.). Leitura de literatura na escola. São Paulo: Parábola, 2013.

DUDENEY, Gavin; HOCLY, Nicky; PEGRUM, Mark. Letramentos digitais. Tradução Marcos Marcionilo. - $1^{\text {a }}$ ed. - São Paulo: Parábola Editorial, 2016.

EVARISTO, Conceição. Olhos d'água. $1^{a}$ ed. Rio de Janeiro: Pallas - Fundação Biblioteca Nacional, 2016.

FARACO, Carlos Alberto. Linguagem \& diálogo: as ideias linguísticas do círculo de Bakhtin. São Paulo: Parábola editorial, 2009.

FOUCAULT, M. A escrita de si. O que é um autor? Lisboa: Passagens. 1992.

INSTITUTO PRÓ-LIVRO - IPL. Retratos da Leitura no Brasil. $4^{\text {a }}$ ed. São Paulo - SP. Disponível em: < https://www.publishnews.com.br/estaticos/uploads/2016/05/zPurbYyLtHcyykd8onwpYk7q z6lopAWUYdDlHbLRAKy1FQWdCNf64T4VIOIZAP7BUJAxYsxkbY73VaWp.pdf >

KLINGER, Diana. Escritas de si, escritas do outro: o retorno do autor e a virada etnográfica. $2^{\text {a }}$ ed. Rio de Janeiro: 7 Letras, 2012.

Revista Moara, n. 56, vol. 2, jan-jul 2021 ISSN: 0104-0944 
LA TAILLE, Yves de. Piaget, Vygotsky, Wallon: teorias psicogenéticas em discussão. $27^{\mathrm{a}}$ ed. - São Paulo: Summus, 2016.

LAJOLO, Marisa. Do mundo da leitura para a leitura do mundo. $2^{\text {a }}$ ed. São Paulo: Ática, 1994.

LARROSA, J. Tecnologias do eu e educação. In: SILVA, T. T. O sujeito da educação. Petrópolis: Vozes, 1994, p. 35-86.

MARCUSCHI, Luiz Antônio. Produção textual, análise de gêneros e compreensão. São Paulo: Parábola editorial, 2008.

OLIVEIRA, Edjane Alves de. Uma proposta metodológica a partir da escrita de si como estratégia de aproximação do leitor infanto-juvenil ao texto literário. 2018. Dissertação (Mestrado Profissional em Letras - PROFLETRAS) - Faculdade de Letras, Universidade Federal do Rio de Janeiro, Rio de Janeiro, 2018.

PETIT, M. A arte de ler ou como resistir à adversidade. Tradução de Artur Bueno e Camila Boldrini. São Paulo: Ed. 34, 2008.

RAGO, Luzia Margareth. A aventura de contar-se: feminismos, escrita de si e invenções da subjetividade. Campinas, SP: Editora da Unicamp, 2013.

ROUXEL Annie. Aspectos metodológicos do ensino da literatura. In. DALVI, M. A.; REZENDE, N. L.; JOVER-FALEIROS, R. (Orgs.). Leitura de Literatura na escola. São Paulo, SP: Parábola, 2013, p. 17-34.

SANTAELLA, L. (2019). O livro como prótese reflexiva. Pontifícia Universidade Católica de São Paulo, Programa de Estudos Pós-Graduados em Tecnologias da Inteligência e Design Digital. São Paulo - SP, Brasil. Disponível em: < https://doi.org/10.11606/issn.1982-8160.v13i3p21-35 >

SCHEFFER, A.M.M. O cronotopo sala de leitura e a formação do leitor literário. Tese de Doutorado. Juiz de Fora, MG - 2019. Disponível em: < file://C:/Users/Admin/Downloads/ANA-MARIA-MORAES-SCHEFFER.pdf >

VIGOTSKY, L. Pensamento e linguagem. São Paulo: Martins Fontes, 1991. 